\title{
ON THE TIME REQUIRED FOR FOREST DUFF TO ATTAIN HYGROSCOPIC EQUILIBRIUM
}

\author{
By H. W. HaRkness
}

\author{
Assistant Professor of Physics, 2ueen's University, Kingston, Ontario
}

T IS well known that the hygroscopic conditions of the top duff is a determining factor in the propagation of a forest fire. A large number of experiments and observations in the field and in the laboratory have demonstrated this. ${ }^{1}$ When the moisture in the top duff is in hygroscopic equilibrium with the moisture in the atmosphere, changes in the relative humidity are followed by corresponding changes in the moisture contents of the duff. As would be expected the duff lags behind the changes in the relative humidity, the lag depending upon the nature of the duff and its state of dispersion and decay. From field observations it is believed that this lag is about two hours. ${ }^{2}$

While undertaking researches in forest fire hazard for Messrs. Price Bros., Ltd., in the Gaspe region of the Province of Quebec, the writer attempted to determine the changes in the moisture contents of top duff which was quite close to very large settlers' fires. Here the duff is under the influence of radiation from the fire, and moisture which is carried over its surface by the considerable convection winds which sweep in towards the fire. The results of these experiments were uncertain due partly to lack of precision attainable in the field and partly due to the fact that instruments often had to be removed from the approaching fire before unequivocal results were obtained. It was clear, however, that there was extremely little drying even in regions unprotected from the direct radiation by shrubs and undergrowth. The moisture carried over the duff by the convection winds might counter-balance any effect due to radiation, but nothing was known about the time required for the duff to absorb moisture when it was exposed to a relative humidity above that with which it is in equilibrium. The problem seemed of such practical importance that a series of laboratory experiments have been conducted with the object of measuring the time required for a sample of duff, in hygroscopic equilibrium with the atmosphere at a given relative humidity, to attain equilibrium with the atmosphere when the relative humidity is instantaneously changed to some higher value.

\footnotetext{
${ }^{1}$ Publications, Dominion Forest Service. Nichols.

Reports of Quebec Forest Industries Association $(1929,30,31)-\mathrm{L}$. H.

2Publications, Dominion Forest Service, Research in Forest Protection, J. G. Wright.
} 


\section{EXPERIMENTAL}

A hygrostat has been built which will maintain the vapour pressure at a desired value for any length of time, and in which the vapour pressure can be quickly changed to a new value which, in its turn, can be maintained. The construction of the hygrostat can be seen from Figure 1. It consists essentially of two compartments $A$ and $B$. The desired vapour pressure is obtained by placing supersaturated solutions of appropriate salts in the shallow glass tray $T$ in the chamber $A$. By means of a fan the air is circulated through the experimental chamber B-the hygrostat properby way of the metal pipes $P$. In this way a constant relative humidity is maintained in $\mathrm{B}$, and a very desirable circulation of air is established over the specimens being studied.
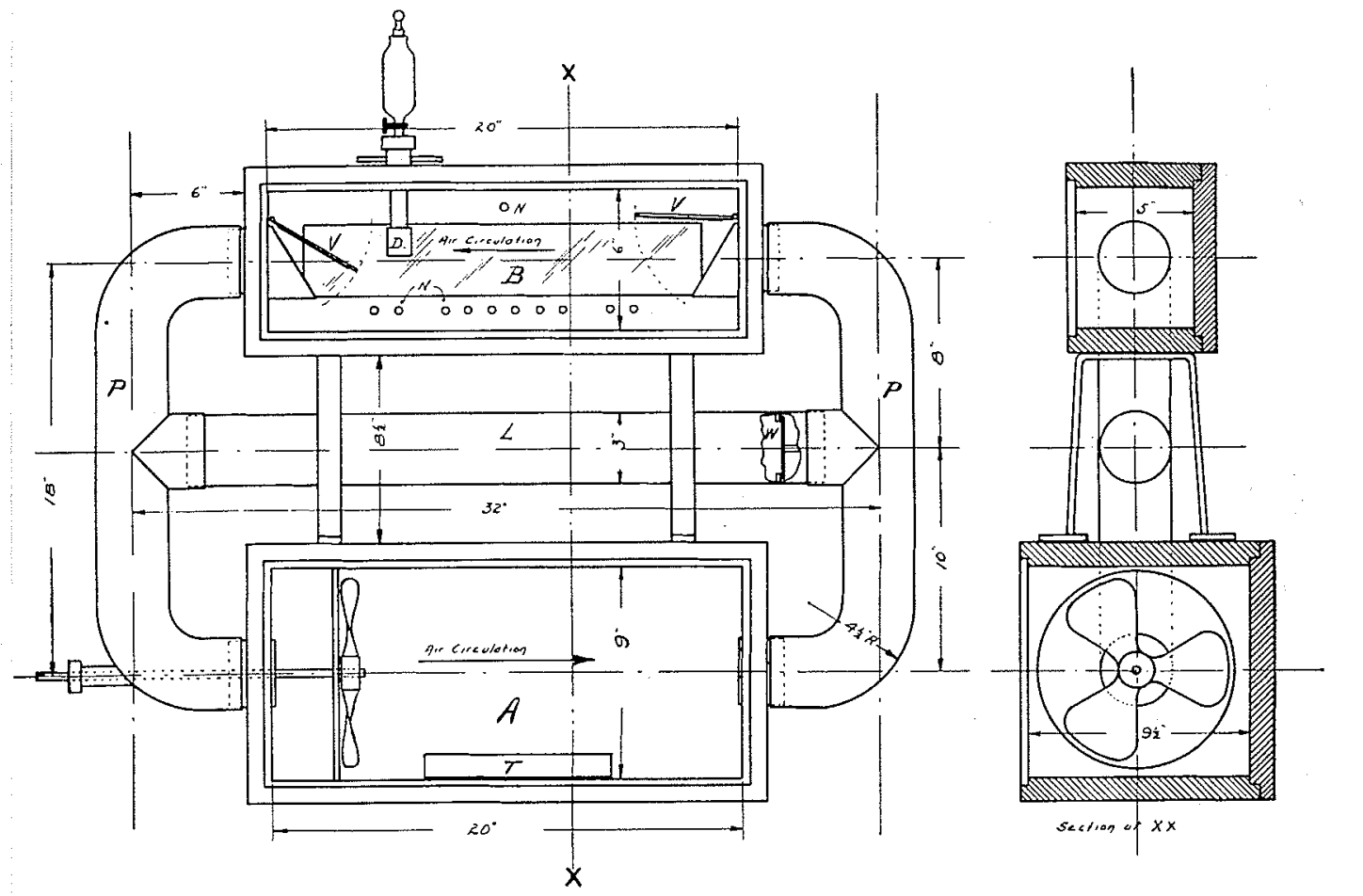

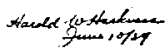

When the relative humidity in $B$ is to be changed, the valves $V$ in the chamber $\mathrm{B}$ are closed and the valve $\mathrm{W}$ in the auxiliary pipe $\mathrm{L}$ is opened, so that the circulation now takes place through this pipe. Chamber $A$ is 
opened, and the tray of solution is replaced by one containing a solution which will maintain a relative humidity higher, or lower as desired, than the existing value in $B$. This operation requires about $30 \mathrm{sec}$. The air is allowed to circulate over this new solution, and through the auxiliary system, for five minutes. Meanwhile the relative humidity in B is sufficiently well maintained at its original value. The valve $W$ is now closed and the valves $\mathrm{V}$ opened to the new air. The relative humidity in $\mathrm{B}$ will attain its new steady value within the time in which it is possible to take a quick reading with the dew-point hygrometer which is incorporated within the hygrostat chamber.

The rear of the chamber $B$ is permanently closed, but the central partition of this wall is of glass. The front is similar to the rear, but is removable and can be quickly clamped into place. The rear wall of chamber $A$ is of wood throughout, but the front is similar to the front of chamber B. There is sufficient glass to allow all parts of the interior of both chambers to be clearly seen. All interior wood surfaces were well oiled and covered with several coats of white enamel. The removable walls of both $A$ and $B$, when in place, are sealed by a rubber gasket.

A number of small copper tubes $N$ (Fig. 1) soldered to copper plates which are screwed to the outside of box B, and packed with rubber gaskets, allow necessary wires to be let into the hygrostat. The wires are sealed into the copper tubes with wax. By means of the small copper tube at the top of the chamber B samples of air can be removed from the hygrostat into a Rideal-Shaw absorption hygrometer.

The dew point hygrometer D, in the chamber B (Fig. 1), has been found very satisfactory. The dew point is observed by means of a thermo-junction welded to the outside of the thimble. The valves $\mathrm{V}$ and $\mathrm{W}$ are faced with rubber and are operated with links and rods which protrude through stuffing boxes fixed into the walls of the pipes $\mathrm{P}$. The rods enable one to clamp all the valves securely in any desired position. The valve $W$ serves to adjust the draught of air over the samples in chamber B as well as to circulate the air over a new solution when preparing to change to a new relative humidity.

Appurtenances which have been added from time to time as the work progressed, and the parts not shown in the diagram can be seen in the photograph of the hygrostat (Fig. 2). All metal parts about the instrument are connected by a system of fine copper wires so that the whole hygrostat is electrically shielded.

The result of a typical test of the performance of the hygrostat is reproduced in Fig. 3. This test was made within the range of relative humidity 


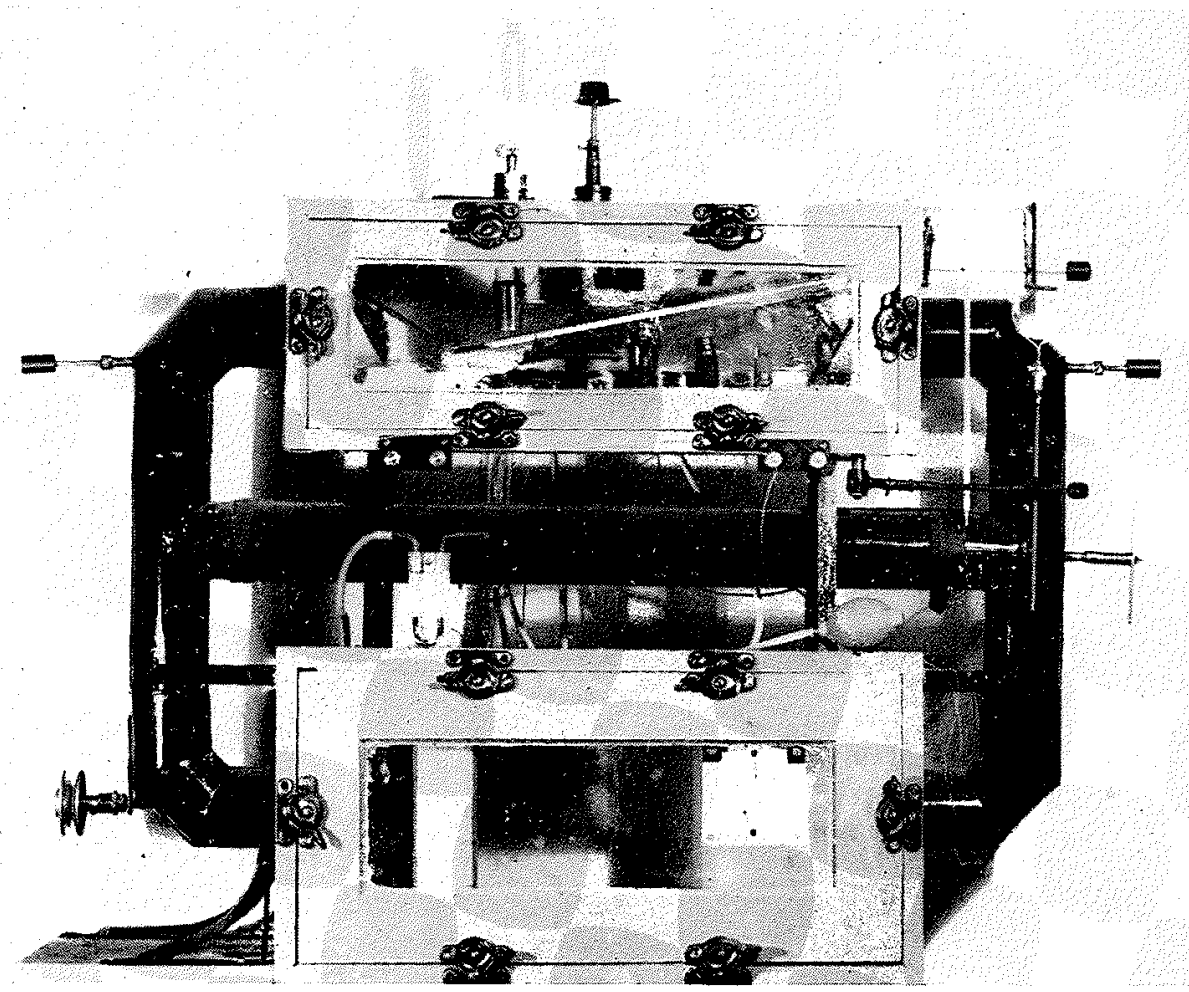

FIG. 2

which was of interest for the problem immediately under investigation. Preliminary tests showed that in this region it is necessary to operate the auxiliary circulation for 5 mins., if the relative humidity is to be lowered by 15 per cent., and for $4 \mathrm{~min}$. if it is raised by that amount. These tests determine the length of time which has been allowed to elapse between the closing and opening of the valves $\mathrm{V}$, as indicated by the arrows $1,2,3$ and 4 in Fig. 3. It will be observed how well the relative humidity is maintained in chamber $B$ during the time it is completely shut off from the regulation chamber A.

The samples here studied, which consisted of whole leaves selected from mixed hardwood stands in the Gaspe region, were placed in the hygrostat, allowed to get into equilibrium with a relative humidity of about 50 per cent. and then the relative humidity was quickly adjusted to and maintained at 80 per cent. The change in moisture contents of the leaf was watched 


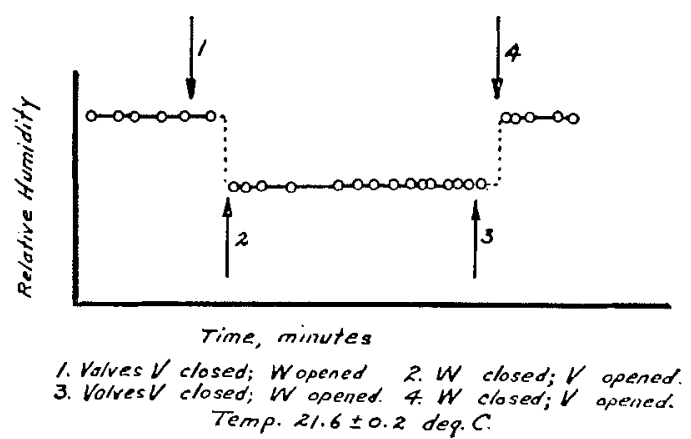

FIG. 3

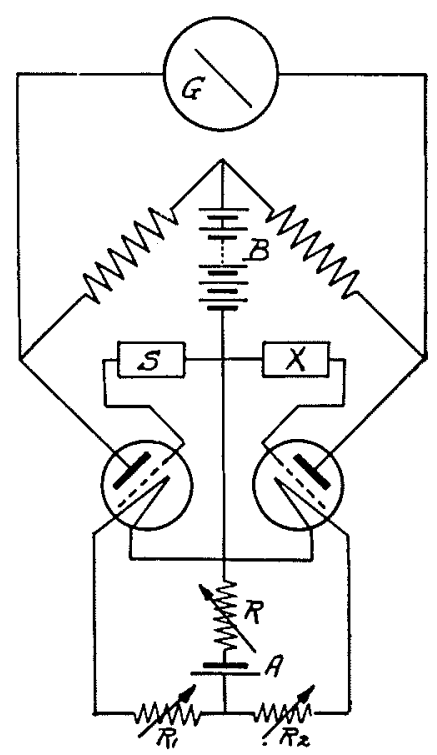

FIG, 4 

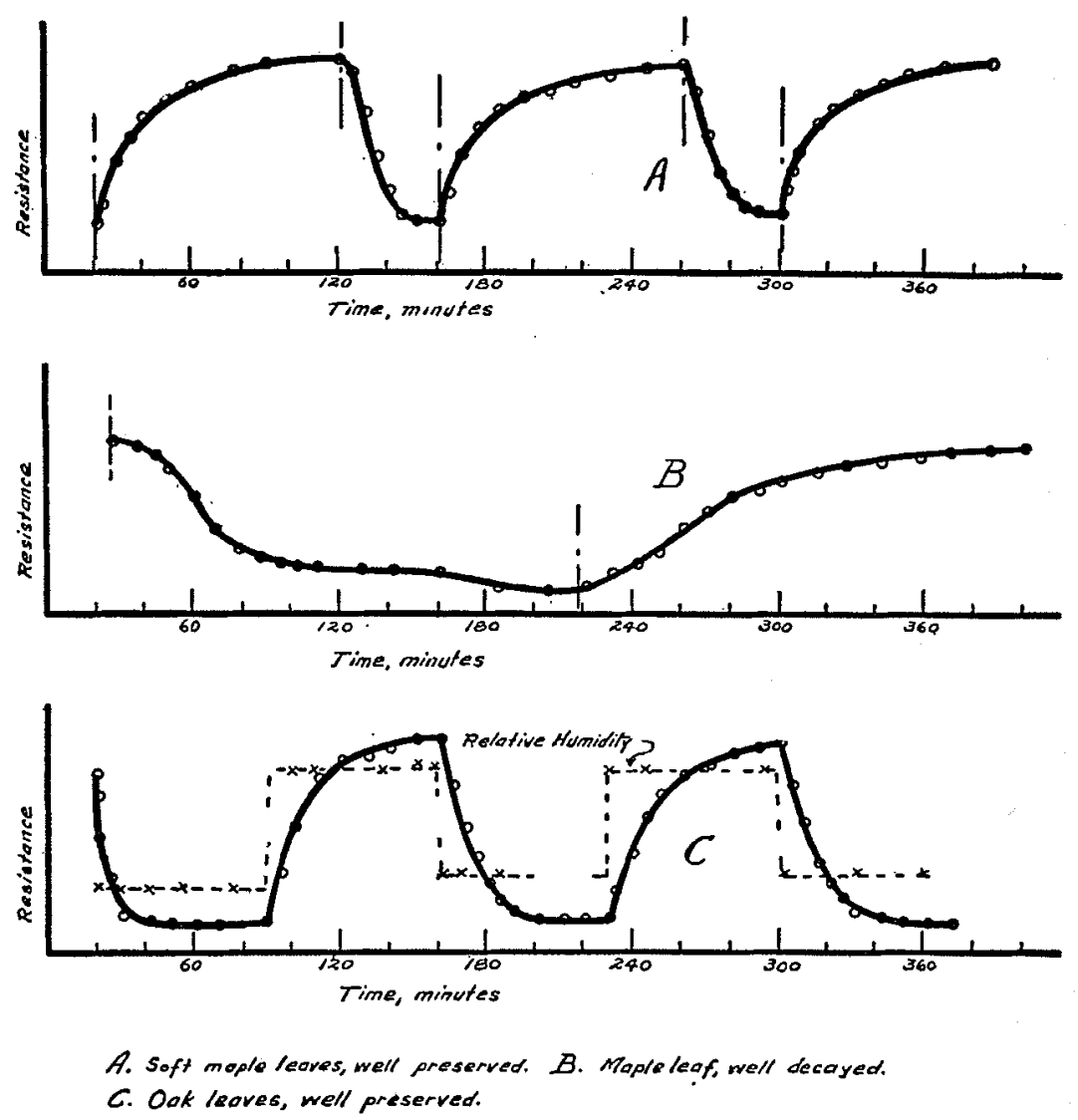

Typical Wetting Curves

FIG. 5

as time progressed and when it was in equilibrium with the higher relative humidity the latter was lowered to 50 per cent. again and so on. In this way the hygroscopic behaviour of a single leaf has been followed for hours on end.

The change in electrical resistance of the samples has been used as a convenient indicator of change in moisture contents. Field experiments reported elsewhere ${ }^{1}$ have shown that when the moisture contents of the duff is in the region here studied resistance measurements repeat themselves when the moisture contents does. The single leaves were clamped between heavy brass jaws to which electrical contact could be made. The leaf was then 
inserted in the grid circuit of a Type 30 tube as shown at $\mathrm{X}$ in Fig. 4. $\mathrm{S}$ is a standard resistance of the same order of magnitude as $\mathrm{X}$. The resistances $R_{1}$ and $R_{2}$ are first adjusted to such values that small alterations in the value of $R$ will not destroy the bridge balance, $S, X$, and the two tubes are placed within the hygrostat, $\mathrm{S}$ being shielded from moisture changes.

\section{DISCUSSION OF RESULTS}

From the point of view of forest fire hazard the results which are of direct interest are the times required for a leaf of any given type to change its moisture contents from that which is in equilibrium at one relative humidity to that in equilibrium with another relative humidity higher or lower than the first. Some typical results are shown graphically in Figure 5 and the average times of a large number of leaves is listed in the table below.

Times for Leaves to Change Their Moisture Contents from that in Equilibrium at 50 Per Cent. Relative Humidity to that at 80 Per Cent.

\begin{tabular}{|c|c|c|c|c|}
\hline & \multicolumn{4}{|c|}{ Time } \\
\hline Leaves, well decayed & & $\begin{array}{l}\text { Wet } \\
\text { mins }\end{array}$ & & $\begin{array}{l}\text { Dry } \\
\text { mins. }\end{array}$ \\
\hline $\mathrm{k}$ Leaves, well preserved & 38 & " & 35 & " \\
\hline Soft Maple Leaves, well decayed & 180 & “ & 180 & " \\
\hline Soft Maple Leaves, well preserved & 60 & " & 22 & “" \\
\hline
\end{tabular}

To be sure, these leaves are not exposed in the way they are when they form components of heterogeneous duff but it is unlikely that the times will be less than those shown here. Any given leaf will, in general, expose less surface to the air in the woods and in addition it may be receiving moisture at a constant rate from lower layers of duff, or its under surface may be constantly exposed to saturated vapour. As a matter of fact the times cannot be directly determined in the field since the changes of relative humidity are continuous. As a modification of these experiments oak leaves have been tested when clamped over the mouth of a beaker containing water, in one case, and a beaker containing a weak solution of sulphuric acid, in another. This simulated to some extent the conditions in the field. The times are substantially the same, the only difference being the absolute values of the moisture contents.

These general results are in agreement with reports from the field (loc sit) that the duff equilibrium moisture lags behind the relative humidity by about two hours. The time is too great to admit of moisture from convection currents round a fire having any great protecting value if the moisture in the duff is much below its safe value. If it is just at or just below the danger point and the relative humidity of the air carried in by convection winds is considerably higher than that surrounding the fire it may give 
marked protection. It will be noticed from the curves reproduced that in the first few minutes the moisture rises considerably and the time is consumed largely in the last stages of coming into equilibrium. The nature of these wetting and drying curves is similar to curves obtained in the study of other hygroscopic materials such as wool and cotton fabrics.

It appears that further work of this nature upon a large variety of leaves in various states of decay and upon different types of duff would yield results of great value in forest fire hazard work. A complete study of the behaviour of duff betwe'en two relative humidities five to ten per cent. apart is desirable.

The author is indebted to Professor Small of the Chemistry Department, Acadia University, for helpful discussions during the progress of this work. Mr. G. W. Walker, Instructor in Physics at the University of New Brunswick, gave valuable assistance in experimental work. 